\title{
Patrimonio gastronómico peruano: realidades y perspectivas para un programa nacional
}

\section{Sergio Zapata Acha}

\section{Introducción}

Cada pueblo, cada región tiene en la alimentación un factor que le posibilita encontrar su propia identidad. Esta identidad culinaria, caracterizada por reflejar realidades de índole diversa, producto de una mayor o menor evolución que integra aspectos del medio ambiente, culturales, sociales y económicos, garantizará su supervivencia. Los resultados se evidencian en cuanto a la variedad de comidas y bebidas, así como el entorno determinado por las costumbres y hábitos de consumo. Por ejemplo, la forma de preparar los alimentos, la presentación, el ordenamiento, los horarios, los platos especiales; todo lo anterior refleja mucho de la realidad y contribuye a la denominación de una cocina determinada.

Más allá de consideraciones históricas, importantes por cierto, quisiéramos ver en los alimentos peruanos tradicionales una fuente de inspiración práctica en cuanto al desarrollo de productos con mayor valor agregado, y con potencial de ser considerados tanto en el mercado nacional como en el marco de la internacionalización y exportación de comidas étnicas. Un ejemplo temprano de interés por el consumo de los productos étnicos más auténticos y cocinas de paises lejanos fue puesto de manifiesto por Comber (1992).
Recientemente, Tailandia se ha embarcado en uno de los proyectos gastronómicos más interesantes del mundo. Planea lanzar una cadena de más de 3000 restaurantes en todo el mundo durante los próximos cinco años. De éstos, 1000 estarán ubicados en Estados Unidos. El plan contempla también aperturas en América Latina. Los restaurantes se caracterizarán por ser de varios tipos: los de comida rápida; los de precios moderados; y los lujosos. Es la primera vez que un gobierno lanza una cadena de restaurantes. "Queremos mostrar al mundo el genuino sabor de la comida tailandesa" (Anónimo, 2001a). Desde 1990, el gobierno tailandés ha enviado a docenas de cocineros al exterior, ha formado una amplia red de abastecedores de comida y vajilla, y ha organizado innumerables eventos en todo el mundo, obteniendo más de US $\$ 6000$ millones al año por concepto de exportaciones de alimentos, y superando los US \$1600 millones en exportaciones de vajilla para restaurantes. Es importante recordar que la demanda de comidas étnicas e insumos tiene una tasa de crecimiento anual del $20 \%$ en Europa, donde sólo entre Inglaterra y Francia superan los $\$ 1000$ millones de dólares.

Este artículo tiene por objetivo presentar una visión de la realidad gastronómica peruana dentro del contexto del concepto del patrimonio, y señalar algunas recomendaciones 
para la formulación de un Programa Nacional de Desarrollo Gastronómico, con miras a la internacionalización de nuestra cocina a través del desarrollo de comidas e insumos que podrían satisfacer la demanda potencial en los mercados de productos étnicos (Zapata, 2000); con una visión integradora entre la gastronomía peruana, la tecnología de alimentos y la comercialización.

\section{I.- Patrimonio y gastronomía}

El patrimonio se refiere al "legado colectivo de cada pueblo" (Arellano, 2000). Por lo tanto denota un legado que posee como característica principal el hecho de ser común. Una de las tendencias que se observa en la actualidad es la de la añoranza por el pasado, hecho que ha calado en la "conciencia colectiva" a nivel mundial.

El concepto de patrimonio parte del de herencia o patrimonio personal y se define a través de términos como tradición, pasado, identidad, cultura, nostalgia. Para Urbano (2000), el patrimonio apunta hacia el pasado, es la herencia recibida por vía paterna: la proyección de la figura del padre dando existencia y nombre a lo que el tiempo ofrece a su prole.

Sin embargo, el factor determinante que define al patrimonio "es su carácter simbólico, su capacidad para representar simbólicamente una identidad". Esto explicaría el cómo y el por qué se movilizan recursos para conservarlo y exponerlo (Schüter y Norrild, 2002).

Más aún, en lugar de ser un simple concepto referido al pasado, durante los últimos veinte años los cientificos sociales han redefinido el patrimonio como un movimiento conservacionista que estuvo convirtiéndose en condición de la última parte del siglo XX. Según algunos autores este movimiento refleja un interés renovado por las memorias colectivas, nacionales, regionales y locales, que hoy parecen ser más importantes que nunca. El patrimonio entonces, es visto como una nueva "conciencia colectiva" que refleja un viraje hacia el pasado. La dimensión de este movimiento ha llegado a proporciones increíbles, con el patrimonio referido a temas tan diversos como la protección de los modos tradicionales de preparar comida, como es el caso de Francia, con normas estatales relativas al patrimonio gastronómico (Csergo,1997).

Los franceses conceptúan el patrimonio como un modo de equilibrar los incesantes cambios del mundo actual, el sentimiento de desarrollo, la aceleración de la historia, la explosión del mundo moderno y la "banalización" de criterios sociales; síntomas todos que requieren nuevos sistemas permanentes e identificables. Tradicionalmente las edificaciones representaban el objeto principal del patrimonio; recientemente los usos y costumbres también han sido declarados como patrimonio cultural. En Francia, hasta los modos específicos de preparar comida son preservados. En este sentido la constitución de la especialidad gastronómica en un objeto de patrimonio es un interesante ejemplo del proceso de "patrimonialización" por el Estado (Csergo,1997).

Según esta autora, la gastronomía es un ejemplo extremo de cómo lo anteriormente dicho ha llegado a tomar cuerpo en aspectos específicos, como la forma tradicional de preparación de las comidas motivando, en el caso francés, la intervención estatal en la política y normalización del patrimonio gastronómico nacional.

Desde 1989, secciones institucionales han participado en la creación de una política de patrimonio culinario francés. El Consejo Nacional de Arte Culinario administra el interés nacional en gastronomia en base a una política conservadora en dos orientaciones. Primero, un enfoque histórico etnográfico legítimo para evaluar la fuerza que vincula al producto con la localidad y a la autenticidad de su memoria. Segundo, este "sitio patrimonial" sigue su curso hacia una "inscripción de gusto" y conocimiento a través de la creación de una política de educación nacional. Este procedimiento es incluido como un nuevo aspecto de la educación a través de un programa denominado "el despertar del gusto", destinado a los niños de las escuelas primarias. Agregariamos que estos "gustos" pueden conducir al turista a una permanente curiosidad por la antropología cultural de las regiones del mundo.

Spaey (1995) define la "gastronomia como la expresión cualitativa del modo de alimentación que caracteriza la cultura alimenticia 
de un país o de una región, y el gastrónomo por lo tanto, representa la suma de conocimientos que se adquieren gracias al olfato y al paladar, lo cual permite el distinguir cualitativamente los sabores de los alimentos y líquidos". Para Revel (1996) "la gastronomía es una sucesión de cambios, conflictos y reconciliaciones entre cocina corriente y cocina con arte, basada en lo artesanal".

Los orígenes de la gastronomía se encuentran en el siglo XVIII, siglo que fue testigo de la multiplicación de restaurantes y del inicio de una literatura crítica de la gastronomía. Se formuló un juicio de valor, una experiencia sensorial. El objetivo de este juicio crítico sensorial fue la calificación del gusto y el establecimiento de la universalidad de criterios sobre "estética gustativa". Estos criterios fueron el medio por el cual el trabajo culinario y, más especificamente la especialidad de la comida local se convirtieron en objeto de arte, "tal como lo es un sitio histórico". Por tanto estos objetos de arte culinarios - igual que cualquier sitio histórico - se convierten en objetos de estudio aún antes de ser objetos de la historia a través de la función de la memoria, pasando a convertirse en objetos de resguardo y conservación.

Csergo ha identificado tres etapas en la evolución gastronómica de Francia. La primera se desarrolla entre el fin del siglo XVII y el inicio del XIX, cuando la especialidad alimentaria local, identificada ya en los recetarios y obras de los siglos XVII y XVIII, se inscribe dentro de la enseñanza que involucraba el conocimiento del territorio nacional.

La segunda se extiende a lo largo del siglo XIX, y es a partir de ella que la especialidad gastronómica vendrá a tener un lugar en la memoria histórica y en la conciencia de pertenecer a una nación. La tercera etapa, que va desde el inicio del siglo XX hasta el final de los años treinta, está relacionada con el desarrollo del "turismo en automóvil", que revoluciona el transporte y permite a los franceses descubrir que se elaboraban cocinas suculentas y apetitosas, no sólo en los mejores restaurantes o en las lujosas residencias parisinas, al conocer y apreciar las cocinas regionales, y luego a su influencia en los centros urbanos, primero en Francia y luego en los demás paises europeos, corriente que no tardaría en manifestarse de manera contundente.
Junto con la evolución del turismo y la estructuración de las redes socio-profesionales que le son inherentes, se enunciaron el concepto de sitio patrimonial, y los procedimientos de "monumentalización" de las especialidades gastronómicas, mientras que se construían los estereotipos culinarios regionales. Sin embago, para comprender esta etapa tendriamos que remontarnos al siglo XVII, época en que aparece el primer mapa geográfico gourmande, concretizándose años después en el proyecto de la "monumentalización" de la especialidad gastronómica. A partir de la formalización de ese inventario metódico, se dio pues el preámbulo necesario para la exploración y luego la conservación patrimonial. Hay que hacer notar que la difusión de tales alcances fue por cierto mínima.

A partir del primer tercio del siglo XIX aparecería una literatura culinaria provinciana, que a nuestro criterio sería de suma importancia en el desarrollo de la gastronomía nacional. Durante la segunda mitad de ese siglo, aparte de los recetarios y de los textos anecdóticos que incluyen comentarios históricos, la gastronomía se arraiga localmente, se construye en el pasado, en el lugar y en su memoria. Esta literatura favorecerá el proceso de valorización patrimonial. Posteriormente, entre 1900 y el inicio de la segunda guerra mundial, esta producción que promueve y celebra la riqueza gastronómica en conjunto no cesará de multiplicarse en diferentes obras. Mencionemos a modo de ejemplo una de ellas, se trata del Trésor gastronomique de la France de De Croze y Curnonsky (1933), donde aparece en forma sistemática la relación de platos, postres y bebidas de cada provincia, adjuntas a un mapa y con una explicación o introducción previas de los autores. Es pues, el tipo de obra necesaria para visualizar en conjunto y definitivamente el desarrollo gastronómico nacional de un país.

Específicamente serán las "guias gastronómicas" los instrumentos que en su momento permitirán el descubrimiento de un pais a través de sus riquezas culinarias, introduciendo un nexo permanente entre el turismo, la historia y la gastronomía. La gastronomía será entonces un elemento de valorización cultural, promotor del turismo, fuente económica, de patrimonio y de sociabilidad, motivando la movilización de 
grupos sociales, redes e intereses que van a converger en la salvaguarda de esa identidad (Csergo, 1997).

Serán sobre todo los hoteleros y restauradores quienes se movilizarán para garantizar el mantenimiento de las cocinas regionales, la preservación de las especialidades locales, la memoria culinaria y la autenticidad del savoirfaire. Bajo la acción conjunta de las asociaciones de gastrónomos, de los profesionales del turismo y la restauración, la cocina y su especialidad accederán oficialmente al estatus de "obra artística". Es importante señalar que en Francia cada provincia tendrá sus "secretos técnicos de cocina", sus recetas ancestrales y su tradición gastronómica, al igual que los paisajes naturales, los monumentos arquitectónicos y la historia como elementos de valorización patrimonial.

Existen, sin embargo, preguntas que surgen luego de plantearse las etapas del proceso común de "patrimonialización" de la especialidad gastronómica junto a los demás "sitios" del patrimonio. De acuerdo con Csergo, la principal interrogante se centra en salvaguardar "la autenticidad" de un objeto con características particulares como la modificación en el tiempo, la transmisión oral o las recetas relativamente recientes, los cambios en el gusto, los diferentes ingredientes. A todo lo dicho, es fundamental ser conscientes de los intereses económicos que se encuentran en juego: la valoración del turismo local, los recursos tradicionales del lugar, que favorecen el mantenimiento y la fortificación de la organización rural, y el equilibrio de la balanza comercial del país.

El turismo es esencial para el movimiento de "patrimonialización" en las últimas décadas y estas prácticas turísticas son reconocidas como culturales y económicas, ayudando a desarrollar la "memoria culinaria". De este modo el turismo es visto como una herramienta de reapropiación de las gastronomías tradicionales. La "patrimonialización" de una espcialidad culinaria está también relacionada con la regeneración económica y la valoración turística de la localidad.

Un proyecto cultural llevado a cabo por el poder público para la preservación de una memoria culinaria que integre, por naturaleza propia, la innovación gastronómica, constituiría locus patrimonialis al mismo nivel de un edificio histórico, que contiene en sí un futuro positivo económico y social. En resumen, la constitución de una tradición colectiva es materia de un nuevo significado que transforma el objeto en "recurso". En el caso de Francia, como en otros países donde el patrimonio es manejado de cerca por el Estado, se dan discursos en los que aparentemente no se critica la mezcla de cultura y comercio.

López (2002), en la experiencia sueca, menciona al turismo como una actividad económica que se vale de la transformación patrimonial, valorándola socialmente, para ofrecer un producto diferenciado y atraer a nuevos segmentos del mercado. Desde esta perspectiva, no basta con que un edificio sea viejo u obsoleto para que se transforme en un bien patrimo nial, sino que es necesario que sea "activado" por algún agente cultural (poder políticoeconómico, mediador cultural, etc.).

El turismo, entendido como actividad económica, tiene el poder de activar elementos del pasado para transformarlos en recursos patrimoniales. Para tener éxito debe haber algo que vender y esto hace que los lugares históricos, el paisaje y la cultura de los habitantes se conviertan en recursos a explotar.

Se denomina patrimonio intangible, a aquel que antes que materialidad o monumento es por ejemplo, sabor, aroma, recetas contadas, maneras de acomodar el cuerpo a ritmos especiales de amasar, hornear, freír, disposición de la mesa, formas de celebrar, maneras de recibir al invitado a la mesa. Tal es el caso de los inmigrantes (rusos, suecos, turcos, italianos) que llegaran a la Argentina a comienzos del siglo XX (1901-1910), ilustrado en el trabajo de Padilla (2002). La incansable repetición de estas recetas y secretos culinarios, gracias a la memoria y los movimientos del cuerpo que guardaron las maneras de recrear texturas y sabores, permitieron conservar el espíritu de lo intangible propios del patrimonio gastronómico.

En los últimos años la industria del turismo ha diversificado sus opciones de redes- 
cubrimiento de recursos a través del patrimonio cultural y artistico. A pesar de ello la gastronomia vista por su capacidad integradora - al comprender aspectos que involucran costum. bres, historia, geografia, religión, economia y vida social - no ha sido profundamente estudiada. Existe, de otro lado, un mercado turístico cambiante debido entre otras razones al aumento en la capacidad adquisitiva, la mayor disponibilidad de tiempo libre, los cambios sociales y demográficos de los paises desarrollados, hechos que han modificado las demandas de los viajeros. Los resultados de estos cambios sociales se traducen en una mayor variedad de turistas (Bernard y Dominguez, 2002).

El uso que hace el turismo del patrimonio determina que la gastronomia adquiera cada vez mayor importancia para promocionar un destino y para captar corrientes turisticas. Es por ejemplo, el caso de las rutas gastronómicas, donde las motivaciones principales se encuentran en la búsqueda de las raices culinarias y la forma de entender a la cultura de un lugar a través de su gastronomia, que están adquiriendo cada vez mayor importancia. Con el objeto de potenciar el atractivo de las diferentes gastronomias locales se han creado en diferentes paises rutas, que comprenden lugares donde la gastronomía tiene caracteristicas similares. Estas pueden estar organizadas en función de un producto o de un rasgo cultural característico que le da su nombre. Las primeras buscan promover el consumo de un producto que se encuentra en abundancia, e incentivar de esta manera el desarrollo de un área rural. Las rutas gastronómicas en función de la cultura tienen por objeto mostrar los valores culturales de determinadas localidades (en Argentina se encuentra la ruta de los inmigrantes; similarmente en Brasil existe la ruta de los colonos italianos). Además de la presentación de los platos típicos se enfatiza la producción del vino, cuyo eje temático lo constituye la uva (Schlüter, 2002).

Se puede concluir entonces, adelantando perspectivas, que en un proyecto cultural donde se maneje adecuadamente la "memoria" culinaria integrando la innovación, la gastronomía constituye un patrimonio portador de beneficios socioeconómicos reales.

\section{II.- Influencia internacional y evolución}

Internacionalmente la cocina francesa es desde hace mucho tiempo sinónimo del "arte en cocina", de gastronomía y en definitiva es "la Cocina" de referencia con todas sus implicancias. Convencionalmente es Ilamada cocina internacional pero en el otro sentido también ha habido una influencia internacional importante sobre ella. ¿Cómo surge y cual es su influencia en la cocina peruana?

La Galia ya era famosa por sus embutidos, quesos y vinos. La cocina medieval se basaba en los binomios dulce y salado, agrio y dulce, lo no graso y las especias. Con el Renacimiento llegaron a Europa nuevas verduras, frutas, especias procedentes de las Américas (pavo, tomates, fréjoles, piña, chocolate, vainilla, cacao, papas, maíz, etc.), hecho que reviste mayor importancia para la evolución de la cocina francesa según Revel (1996), que aquellos hechos, casi imaginarios, ligados a la presencia de Catalina de Medicis y sus cocineros en la corte de Francia a mediados del siglo XVI.

En este mismo siglo, el desarrollo de la imprenta permitirá una amplia difusión de las obras dedicadas a la cocina, pero habrá que esperar hasta el siglo XIX para encontrar precisiones sobre el tiempo de cocción o las proporciones de los ingredientes. A mediados del siglo XVII se produce la sustitución de una cocina basada en la yuxtaposición y la acumulación, la mezcla de especias, por otra cocina más sutil, basada en combinaciones, fondos de salsa, cocciones separadas, y el uso delicado de hierbas aromáticas (Revel, 1996). Luis XVI y el siglo XVII francés le concedieron importancia a la etiqueta (conjunto y costumbres que se debían seguir en la corte). Época en la que se fomentó el servicio a la francesa (todos los platos se siven al mismo tiempo, siendo la disposición de los comensales en la mesa muy precisa). También las recetas son estructuradas, proponiéndose un modelo francés exportable a los medios burgueses y a las cortes extranjeras. A partir de 1750 es clave la "ligazón" en la cocina francesa, aplicándose en la confección de 
salsas y "ligarlas". La corte francesa es entonces la sede de la gran cocina, ya que la comida se convierte en un instrumento de gobierno e influencia política. La gran revolución gastronómica data del siglo XVIII, abriéndose en 1765 el primer restaurante. Fórmula que se propaga con éxito entre 1790 y 1814 cuando los grandes cocineros particulares se ven privados de sus empleos por causas políticas generadas por la revolución.

En el siglo XIX la cocina de Carême enfatiza el sabor (gustos y aromas) en sus relaciones mutuas, en su interacción. La complejidad decorativa precedente es modificada, tendiéndose a su simplificación (Revel, 1996). La utilización de la mantequilla se convertirá pues en signo decisivo de la gran cocina francesa. Así llegamos a la cocina consistente y burguesa de la Tercera República (1870-1940), compuesta por menúes interminables, que sólo se verá interrumpida en los años 70 con la llegada de la nouvelle cuisine, preocupada ésta por la dietética. Paralelamente se establecieron nuevos cánones de estética corporal y se adoptarian nuevas patrones alimenticios. Todo esto influyó en los hábitos y gustos, y por consiguiente, en los cánones culinarios. De acuerdo con Revel (1996), "La nouvelle cuisine fracasó por el uso fácil de especias, no saber matizar y por lo difícil que es lograr un equilibrio entre lo normal y la complejidad profesional". Entonces, tras una generación que pecó frecuentemente de excesos, la cocina francesa inició, a finales de los 80 , una vuelta a los productos regionales auténticos, sin renunciar a la lección de sutileza que había recibido de la nouvelle cuisine (Yacar, 2000).

Podemos entonces resumir la evolución de la cocina y pastelería francesas como el proceso que se llevó a cabo particularmente a lo largo de doscientos años -a partir del siglo XVII- desarrollándose en función de los gustos de los consumidores, y que tuvo por características principales la adopción de una serie de ingredientes provenientes sobretodo de las Américas, junto con el desarrollo de una amplia variedad de platos y de los llamados "fondos" y salsas sutiles, logrados con la correcta combinación y armonía de sus componentes. A inicios del siglo XIX la cocina francesa clásica comienza a invadir el mundo gracias a la apari- ción de célebres cocineros y gastrónomos, quienes a través de sus recetas y libros hicieron posible tal difusión y aceptación.

La influencia culinaria francesa en el Perú se inicia mayormente en las postrimerías de la Emancipación. Esta influencia resulta notoria ya a finales del siglo XIX e inicios del XX, tanto en los banquetes de las clases altas como en los libros de cocina de la época, observándose sobre todo en la adopción y uso de ciertos términos como chef, cuisine, bufete, menú, mayonesa, vol au vent, chantilly, para terminar en los últimos años con la difusión y edición de recetas de mousse au chocolat y quiches, que aparecen en algunos recetarios peruanos (Gorritti,1890; Anónimo, 1895; Anónimo, 1896; Anónimo, 1918; Boix, 1928).

Sin embargo, y a pesar de su innegable influencia, la cocina criolla en sí no se ve modificada en su esencia, dándose estos cambios en los hábitos y la presentación de comidas (servicio y etiqueta), correspondiendo más bien a la cocina culta su materialización en comidas con un carácter más internacional.

La evolución culinaria está caracterizada por ciclos de innovación (modificación de sabores) y por ciclos conservadores, donde prima lo establecido (seguridad y protección). Ambas tendencias son a la larga parte del mecanismo o fuerza motriz que permite el desarrollo de la cocina.

En cuanto a la evolución de la cocina peruana, resulta claro que el mestizaje - "una larga historia de aceptaciones, adaptaciones, aperturas" según Cisneros (1995) -, y los cambios que se sucedieron en los tres siglos, siguientes a la Conquista, le dieron origen, identidad y nombre propio, al pasar por periodos formativos iniciales y de transición, alcanzando luego una etapa que podriamos calificar como clásica (entre mediados del siglo XIX y mediados del $X X)$, para llegar en la actualidad a una nueva etapa (de transición) con influencia internacional diversa. Los españoles trajeron sus recetas y condimentos, y con el descubrimiento de "nuevos" productos dieron el impulso inicial para muchas modificaciones. La cocina española, por tanto, forma parte del 
origen de la peruana, y no es que se haya "ligado" a ella.

La cocina peruana se inicia cuando los indigenas pudieron cultivar las plantas y aclimatar los animales traidos por los españoles, lo que permitio a su vez modificaciones en la cocina autoctona, produciéndose entonces una simultanea y doble corriente de modificaciones en las comidas de españoles, indigenas y mestizos, con adopción de nuevas posibilidades culinarias. En esta etapa la Iglesia tuvo un papel importante en la cocina del pais, con la adaptación de las recetas ibéricas recurriendo a ingredientes locales que recordaban a los originales, dándose asi una via de entrada en los hogares de las familias españolas y criollas.

En el transcurso del siglo XIX el latifundio genero una agricultura comercial inserta en el mercado internacional (Peloso, 1988), generándose un déficit permanente de la agricultura de subsistencia y produciéndose una disminución en la variedad de productos. Puesto que la comida no entra en conflicto con valores ideológicos, religiosos o políticos, puede subsistir sin riesgos para los modelos dominantes o de unidad nacionales (Vargas,1995). Los desarrollos regionales jugaron un papel importante en la formación de las cocinas nacionales, caracterizadas por una multiplicidad de productos y platos. Esta evolución en general está marcada por ciclos o fluctuaciones de la cocina que van desde lo recargado a lo simple, de lo anónimo a lo artístico, y de lo popular a lo culto.

En años recientes ha aparecido en un marco de creatividad culinaria la llamada cocina "novoandina", cuyos postulados proponen recuperar productos autóctonos y estilos culinarios propios combinándolos con el uso de técnicas modernas y formas de presentación más sofisticadas. Aunque muchas veces se trata más bien de probar ingredientes autóctonos con una diferente preparación o acondicionamiento, en combinaciones distintas a las conocidas tradicionalmente. Por ejemplo, el uso de salsas en base a frutas nativas en platos de tipo "segundo", y no solamente en postres. Ahora bien, según algunos entendidos "el peruano difícilmente come algo que no conoce "(cocina "novoandina")" y "si internamente no logramos introducir el producto, internacionalmente nos irá peor" (Anónimo, 2000). Razón por la cual resultaria necesaria su adecuada difusión, teniendo en cuenta el mercado nacional. Podríamos entonces citar a Revel (1996), quien sostiene que "un chef que pierde contacto con lo popular raramente tiene éxito en sus preparaciones".

De acuerdo con Vesa (1997), podemos agregar que "sólo la aceptación de las masas le dará a la receta su pasaporte de"... peruana. Como diria Revel (1996), la cocina popular anónima, donde no hay un inventor particular, la peruana en nuestro caso, evoluciona lenta y silenciosamente pero sin descartar la innovación, la fantasía de algunos artistas que impiden su estancamiento.

\section{III.- Preferencias nacionales}

En un reciente trabajo sobre los alimentos y bebidas tradicionales de la cocina peruana (Zapata,2001), señalamos los elementos de base generalmente utilizados como: la papa, el maíz, el pescado, el ají, y los varios tipos de chicha, la bebida tradicional vigente, en los grupos más populares y en las provincias. Pese a existir clesde los inicios formativos de la nación peruana una actitud critica hacia la bebida fermentada de maiz, que en realidad es una cerveza, no sucede lo mismo en el caso de la chicha morada, bebida sin fermentar. Desde una perspectiva técnica y de mercado resulta pertinente considerar la solución de aspectos de calidad, homogeneidad, higiene, envases y estrategia de marketing para revertir esta situación, sobre todo con respecto a la primera de las nombradas.

Entonces, si quisiéramos resumir los gustos de los peruanos en términos de comidas, tendríamos en general que mencionar aquellos platos cuya preferencia hace que resulten más representativos de la cocina peruana. Asi podemos tener una idea de las tendencias. Según una encuesta realizada en Lima por Imasen hace pocos años (Valderrama, 1998), los resultados en orden de preferencia fueron: cebiche, papa a la huancaína, carapulcra, arroz con pollo, seco de cabrito, etc. En cuanto a los postres, las preferencias señalaron a la gelatina, mazamorra morada, arroz con leche, crema vol- 
teada, etc. La conclusión que arrojan estos resultados es una situación donde se presenta un fenómeno de sustitución en el consumo de platos extranjeros que reemplazan a los de origen nacional. Esto implicaría la pérdida de cierta tradición culinaria. Este fenómeno no es nuevo, tal como lo señala Lovera (1998) para el caso venezolano.

El Perú es un país caracterizado por poseer un mercado de comidas complicado por múltiples razones. Existen en primer lugar varias cocinas regionales, cuyo resultado es una abundancia de gustos y preferencias locales diferentes. Esto supone en primer lugar haber podido estudiar a profundidad estas cocinas regionales. Sin embargo es una realidad la casi ausencia de recetarios regionales auténticamente tradicionales.

Existe, de otra parte, una tradición culinaria autóctona marcada por la originalidad, pero también caracterizada por comidas de sabores intensos (independientemente de la clase social a la que pertenezca el peruano, siempre está en busca del sabor) y más o menos directos, el uso limitado de vegetales, platos que requieren de largos períodos de cocción y el uso generalizado ( $y$ muchas veces excesivo) del aji y los condimentos, resultando en una comida pesada, pero susceptible de ser renovada técnicamente. Citaremos como ejemplo la cocina piurana, donde aparte del uso importante del ají, la especia significativamente utilizada como colorante y saborizante en la preparación de platos típicos es el achiote (Hoquemghem y Monzón, 1995); y como ejemplo de "innovación - renovación" al ceviche de mérou que aparece en la última edición del Diccionario Gastronómico Larousse (2000).

\section{IV.- Internacionalización de la cocina peruana}

En primer lugar existe la necesidad del estudio serio, sistemático y profundo del origen y evolución de la cocina criolla y nacional, basado en fuentes primarias reales. Resulta pues fundamental descartar los estereotipos y afirmaciones subjetivas y muchas veces fantasiosas que se ven repetidas $\sin$ objetividad. Surgen entonces preguntas como: ¿Han sido las vísceras destinadas sólo para consumo de las clases inferiores?, ¿Cúal ha sido el verdadero grado del aporte africano, árabe, chino, italiano, francés o japonés en la cocina nacional, de haberlo habido en cada caso? Sobre este último punto consideramos imprescindible para cada "legado" la respuesta sustentada en los estudios y análisis cualitativos y cuantitativos de recetarios y manuscritos, las técnicas de cocción, los utensilios de cocina, las abstenciones y ayunos alimentarios, los aspectos socioculturales de aceptabilidad-rechazo y escalas de valores de los alimentos, entre otros aspectos. Otro tipo de interrogante que puede darse es, por ejemplo, ¿Cómo era realmente la comida del pueblo y la nobleza de los Moche? También surgen temas más específicos como: ¿cuál ha sido el grado de la interrelación mexicana, por ejemplo en la dulcería nacional, que aparece presente en recetarios del siglo XIX editados en el sur peruano? (Anónimo,1896).

Otro aspecto importante para el éxito y aceptación en el mercado de comidas étnicas es el requisito de ser preparadas realmente en forma auténtica, con los ingredientes originales, a partir del empleo de recetas tradicionales. Además hay que educar al consumidor en el uso de ciertos ingredientes, salsas, modos de preparación, utensilios, etc. Aquí juegan un papel importante los medios de comunicación en términos de promoción e información.

De otro lado hay que remarcar que las cocinas de países lejanos son percibidas en cuanto a la ventaja del uso de menor cantidad de carnes y más vegetales, y por lo tanto con mayores beneficios para la salud.

Nosotros proponemos en este trabajo el desarrollo de un Programa Nacional del Patrimonio Gastronómico Peruano, con miras a su internacionalización, teniendo en consideración las siguientes etapas:

\section{Estandarización}

Se trata básicamente de establecer un orden, de presentar recetas y fórmulas internacionales de los platos y bebidas más representativos. En una palabra, necesitamos "definir" la cocina peruana y en consecuencia analizar re- 
cetas, etapa por etapa, y normalizarlas. Es en suma una labor que tipifica y uniformiza la preparación y la presentación de las comidas y bebidas más representativas.

De esta manera sentaríamos realmente las bases que van a favorecer una cocina peruana "internacional". Ahora bien, surge inmediatamente la necesidad de una concertación previa, de abrir el debate serio y bien fundamentado, con participación del público, del sector ho-telero, de los restaurantes más representativos, de las asociaciones gastronómicas; con reuniones periódicas cuyo principal objetivo sería determinar los ingredientes y la preparación exactos de cada uno de los platos.

\section{Concertación culinaria}

En esta etapa es fundamental evitar la improvisación en materia de discusión culinaria. A nivel internacional existen asociaciones gastronómicas cuyos miembros son conocedores y aficionados a la gastronomía. Estas asociaciones constituyen el baluarte contra las falsificaciones culinarias, evitando cambios arbitrarios, y la pérdida de autenticidad de recetas originales. Su presencia resulta importante para la salvaguarda y la defensa de la gastronomía nacional. Tienen en su accionar tareas gastronómicas (cursos de cocina, ferias, publicación de libros), desarrollo gremial, apoyo a empresas de la restauración, y capacitación. En nuestro caso, la Academia Peruana de Gastronomía creada en febrero de 2001 tiene por objetivos: promover los estudios de la gastronomía peruana, incentivar la creatividad culinaria en base a productos nativos, defender las tradiciones gastronómicas del Perú y divulgar los conocimientos al respecto, propiciando su aceptación y estima a nivel internacional.

\section{Selección}

Existe la necesidad impostergable de seleccionar platos, sin embargo en forma simultánea es necesario mantener la identidad al ofrecer nuestra cocina al turismo internacional. El objetivo sería presentar una comida peruana total y no tanto clasificada por regiones (para los turistas).

Uno de los problemas consiste en saber de qué manera las sucesivas adaptaciones, en función a las ofertas recibidas, pueden ser materializadas, en una suerte de abanico que vaya desde la presentación de platos rigurosamente ortodoxos (tradicionales) - de acuerdo con los resultados de las investigaciones - hasta presentaciones modificadas (variantes) de estos platos, bajo la forma de comidas más sencillas, de acuerdo con las exigencias del turismo y de acuerdo con las actuales tendencias, como es el resurgimiento y el retorno a la cocina ecológica y de raíces populares, a una alimentación más sana y natural, de sabores auténticos y valorando completamente las bondades de los productos.

\section{Restaurar el sabor tradicional}

En parte y gracias a la Tecnología Alimentaria, es posible ofrecer y garantizar la calidad homogénea, conservación, palatabilidad, disponibilidad regular de ingredientes y productos elaborados, y platos preparados. Se busca pues certificar el buen manejo de alimentos en los restaurantes. Un medio importante y fundamental para incentivar a los clientes en el consumo de comidas étnicas es la presencia del restaurante típico. Sin embargo surge aquí una limitación debida a la imposibilidad de reproducir fidedignamente el sabor tradicional (auténtico) de las comidas de un período determinado. Si estamos de acuerdo en que "todo es costumbre, y la costumbre no se define jamás con precisión porque se sobreentiende, de manera que casi es imposible reconstruirla. La cocina viaja mal en el espacio y en el tiempo, e incluso con las informaciones culinarias sucede lo mismo, es más la cocina regional no viaja" (Revel, 1996). La cocina regional es más de carácter rutinario, tradicional y es transmitida oralmente. Agregaríamos a lo anterior diferencias que ocurren con el tiempo en ingredientes y productos, técnicas de preparación, utensilios, además de la variación en los gustos.

Ver la cocina nacional bajo un contexto de tendencias mundiales permite afinar la conciencia gastronómica y hacer que nuestra cocina adquiera carta de ciudadanía universal. La cocina peruana la tendríamos que suavizar, respetando recetas, pero disminuyendo la cantidad de condimentos, para "adaptarla" al gusto del turista. Es necesario insistir en el desarrollo de los sabores que el paladar extranjero acepta. 
Mucho del empleo futuro está en el Sector Turismo y para las personas que vienen a visitar el país y a disfrutar de su comida, hay que procurar que ésta sea adecuada, haciéndola agradable a la vista y suavizando el gusto, las cantidades convenientemente servidas, tal como lo han hecho en México por ejemplo.

\section{Divulgación - Difusión}

Es importante no sólo conservar sino también difundir la cocina nacional a nivel internacional. Una política debe ser la de ofrecer a los visitantes la posibilidad de probar las bondades de nuestra cocina basada en recetas locales.

A la investigación y análisis de nuestras "cocinas", le sigue la difusión de resultados mediante los medios de información masiva. Además de esa vía están también los profesionales del turismo, el sector de restauración y los estudiantes de las Escuelas de Gastronomía.

La difusión de nuestra gastronomía mediante la participación en eventos nacionales e internacionales (ferias, festivales gastronómicos, demostraciones culinarias), es un aspecto fundamental a tomarse en consideración, tanto como la exportación de productos terminados (bebidas gasificadas, cervezas y vinos nacionales; alimentos congelados; granos secos para el abastecimiento de cadenas de almacenes y restaurantes) (Anónimo, 2001 b). En muchos casos éstos deberán ser reformulados de acuerdo con las gustos (ej. chicha morada en China) y exigencias del mercado (procesos, empaques, condiciones de almacenamiento).

Simultáneamente deberá iniciarse un proceso informativo-educativo de la cocina peruana en los mercados a los que apunta su distribución, facilitando esta tarea la preparación de un catálogo gastronómico y de productos étnicos, generar una base de datos sobre éstos atractivos y un mapa de localización, y remarcar la conveniencia de combinar recursos gastronómicos regionales con aspectos artísticosculturales y recursos naturales (Bernard y Domínguez, 2002).

Otra vía posible para la divulgación de nuestra culinaria consiste en enviar chefs peru- anos a las embajadas y hoteles del mundo para hacer conocer nuestra cocina.

\section{Comercialización}

En la actualidad el principal problema que tiene el Perú para acceder a los mercados internacionales está tanto en la adecuación de los productos a los gustos foráneos como en la continuidad de su abastecimiento.

Un problema que frena la internacionalización de nuestra cocina es el descuido en su comercialización. En varios de los casos de comercialización hacia el exterior tenemos la necesidad de un mayor estudio y más promoción. Mencionaremos el caso de la lúcuma, fruta que constituía parte de la dieta de los moches e incas. Existe una real posibilidad para el desarrollo de nuevos productos derivados de esta fruta como son: pulpa congelada y deshidratada, yogurt, helados, mermeladas dietéticas, flanes, purés, caramelos, rellenos para pastelería. Sin embargo es imprescindible conocer su composición físicoquímica, nutricional y organoléptica, además de posibles beneficios para la salud (propiedad antioxidante).

En el caso de los potajes andinos, vemos que éstos han tenido un escaso mercadeo internacional hasta el momento, y al hablar de los seudocereales falta el conocimiento de los hábitos nutricionales y la información destinada a los mercados objetivos. Existe además muchas veces una pobre calidad de ingredientes utilizados en la preparación de los platos.

Falta pues una adecuada promoción y difusión de las cualidades de nuestra cocina y nuestros productos, y por consiguiente es necesaria una estrategia conjunta de promoción entre productores-gobierno que valore "lo nuestro". Surge entonces la necesidad de asociación entre los productores (para lograr una mejor productividad, estandarización de calidad y volúmenes significativos de venta). $Y$ no menos importante, el conocimiento de la demanda en los países compradores potenciales, los volúmenes requeridos y las preferencias del consumidor final. Una forma efectiva de salvar estas limitaciones se da con la organización directa de ferias de ethnic foods, la promoción 
directa en los mercados y los programas de desarrollo de éstos.

\section{Capacitación}

La importancia de la revalorización del chef nacional para alcanzar niveles internacionales de competencia es fundamental. Por lo tanto es importante contar con centros de formación y escuelas de enseñanza con capacidad para formar el tipo de profesional con estas características de excelencia.

De otro lado es necesario impartir conocimientos gastronómicos a los guias de tu rismo, así como a los delegados culturales de nuestras embajadas, y considerar trabajos multidisciplinarios de investigación dirigidos a obtener conocimientos integrales en gastronomía latinoamericana.

\section{Diversificación-Innovación- Modernización}

La diversificación, la innovación y la modernización son características a ser consideradas para poder conquistar mercados exteriores.

Entre las razones del crecimiento en la demanda gastronómica en los paises desarrollados tenemos:

- Una creciente importancia del turismo y el descubrimiento de nuevas cocinas.

- Un interés por probar nuevos sabores exóticos.

- Un interés por disponer de una mayor variedad de nuevas comidas para escoger.

Dentro de la estrategia de marketing, el mayor porcentaje de la absorción de la información se realiza visualmente, surgiendo entonces la necesidad del desarrollo de un marketing sensorial para los nuevos productos, que incluya el tacto y los aromas. Tal vez debamos hablar de una depuración de la comida peruana, considerando el aligeramiento de los platos y, como ya lo hemos señalado anteriormente, un menor uso de condimentos, incluyendo al ají, a fin de que se pueda internacionalizar.

Ciertamente el ingreso de nuestra cocina al mundo moderno va a permitirnos superar las exigencias cada vez mayores de una comida ligera en calorías y rápida en términos de consumo, mientras que conciliamos las preparaciones con nuestras costumbres y tradiciones de buen comer.

La posibilidad de modernización de la cocina regional debe tener presente la actual tendencia a cocinar en un mínimo de tiempo para conservar aromas y obtener salsas más ligeras. Se trata también, en sentido inverso, de adaptar la experiencia culinaria externa al gusto de los clientes en el ámbito interno.

Últimamente se habla de la cuisine fonctionnelle, cuyo objetivo es "obtener platos que nos mantengan jóvenes y bellos con una pizca de sazón". Debemos considerar entonces a los "alimentos funcionales" (productos que toman en cuenta el origen con un doble propósito, el aspecto nutricional y el de salud). Sus características principales son poseer un efecto terapéutico natural, potenciar sus ingredientes básicos para ser más saludables, o haber retirado sustancias nocivas de su estructura.

La innovación recurre también al estudio de la interacción en procesos físicos y cocina, permitiendo el acercamiento de dos mundos, cuyo objetivo es analizar procedimientos culinarios ancestrales y los refranes basados en observación empírica, para luego incorporar útiles e ingredientes gracias a la comprensión científica de su fabricación.

Las primeras civilizaciones, dentro de las cuales se encuentran los Incas, usaban especias para conectar la dieta con la salud. Por ejemplo, los ajíes se han usado desde tiempos prehistóricos como una valiosa medicina; el paico fue usado para el tratamiento de parásitos intestinales, aparte de constituir una hierba aromática apreciada en la preparación de determinadas comidas. Comenzamos a darnos cuenta de que el desarrollo de nuevos productos sólo tendrá éxito cuando se combinen, tecnología y habilidad culinaria (Uhl, 2000). 
El papel del chef industrial esta creciendo en número y funciones, dándose en la medida que las compañias alimentarias hacen frente a una creciente presión competitiva dirigida a acelerar y mejorar las ofertas de nuevos productos. Mucha de la actividad en el segmento manufacturero está concentrada en mejorar los pertiles de sabor de los ingredientes y las características de rendimiento para su uso en productos al por menor. A inicios de los noventa se presentó una explosión de nuevos e innovadores restaurantes étnicos, así como la proliferación de tiendas relacionadas con la cocina y la comida. Sin embargo cuando los consumidores iban en pos de estos sabores, muchos de los ingredientes que buscaban no estaban disponibles. Frente a la limitación por parte de las empresas de contratar a cientos de chefs, éstas decidieron que podían hacer que sus tecnólogos "pensarán" más como tales, introduciendo con este fin sesiones de aprendizaje culinario dirigidas al personal de investigación. Estas sesiones de entrenamiento culinario se caracterizan por orientarse a la investigación de recetas y desarrollo de sabores, preparación de comidas, y maneras que permitan refinar los ingredientes básicos para una mayor diferenciación del producto. Compañías como McCormick mantienen un centro culinario y sus chefs se han especializado en sabores étnicos, sus usos y en la adaptación de estos sabores especiales e ingredientes en los alimentos. La clave del éxito en el nuevo enfoque es la estrecha sinergia entre el arte del chef y la ciencia del tecnólogo de alimentos, con un trabajo de ambos lados muy ligado y sin perder sus respectivas identidades ("visión gastronómica y visión comercial").

El objetivo es desarrollar soluciones al problema de lievar a escala industrial un concepto de cocina que se deberá traducir en un producto envasado económicamente eficiente. Generalmente estos retos son de dos categorías:

-Sabores para cocinar y de cocinas. Los sabores para cocinar incluyen asado, parrilla y salteado.

-Las cocinas incluyen la Asiática, Latina, Caribeña y los nuevos conceptos de fusión. En esto ultimo resulta básico como chefs poder definir claramente el "concepto de una determinada cocina", haciendo posible apoyar el desarrollo de un producto balanceado de sabor completo, incluyendo su envase.

La idea es desarrollar productos al menudeo que compitan con sus contrapartes de servicios en restaurantes. Por ese motivo la industria alimentaria y las compañías de ingredientes mantienen sus cuadros técnicos al día, incentivándolos para que partan de las raíces a través de viajes frecuentes para visitar restaurantes dentro y fuera del país. "Los chefs deben comenzar a pensar más como científicos y los científicos tienen que comenzar a pensar más como chefs" (Hollingswort, 2000).

La comprensión de las culturas (sus gustos, los métodos para cocinar, los aspectos religiosos, los modos de comer, y la forma de prevenir enfermedades manteniéndose sanos) es una herramienta importante para la creación exitosa de productos destinados al consumidor cambiante (Hollingswort, 2000).

Desde un inicio debemos aceptar la posibilidad de realizar cambios o modificaciones originados por gustos diferentes. Un ejemplo venido de Tailandia es el caso de la sopa tom yam que tendría que ser muy picante, pero en Estados Unidos la hacen suave (Anónimo, 2001a).

En el caso de la oferta citemos el ejemplo observado en el mercado de hamburguesas nacionales donde conocidas cadenas de Comida Rápida han desarrollado productos adaptados al gusto local, sin que por ello hayan modificado la base y la tecnología empleadas. Sin embargo, esto no sucedió en los servicios de comidas rápidas mexicanas, donde no hubo la aceptación necesaria para continuar en el mercado. Ahora bien, si analizamos la posible demanda de comidas peruanas, podemos señalar que nuestra cocina es poco conocida en el extranjero, hallándose muy poco difundida entre otras razones por la casi inexistencia de restaurantes de comida peruana.

El desarrollo de nuevos productos, materia de adaptación o innovación válidas, requerirá nuestra mayor atención y tendrá una importancia clave en la permanente e intensa 
actividad de presentación de las comidas, bases y salsas, postres e ingredientes.

Desde el punto de vista gastronómico, una preparación culinaria constituye la síntesis y la culminación exitosa de las etapas y operaciones necesarias en la conservación y/o transformación de todas y cada una de las materias primas e ingredientes que entran en la producción de un plato específico, así como en el proceso de elaboración de éste. De acuerdo con este concepto y para que los desarrollos sean factibles, tendriamos que aplicar, además de los conocimientos culinarios, procesos tecnológicos adecuados, presentaciones convenientes, cumplir con los requerimientos físico-químicos, nutricionales, de higiene, además de considerar los gustos y preferencias de los consumidores. Esto último como resultado de la investigación y análisis sensoriales, dentro de una eficiente política de promoción y marketing.

Para internacionalizar hay que volver a las raices, restaurar sabores olvidados, ingredientes originales, técnicas de preparación. En este aspecto "el gastrónomo ni se siente prisionero de la tradición, ni se deja impresionar por la novedad" (Revel, 1996). En algunos casos es posible la internacionalización respetando los principios del plato y el espíritu de éste, siendo entonces las recetas susceptibles de ser mejoradas y refinadas. En otros casos es imposible hacerlo, produciéndose una "despersonalización". Como causas de esta imposibilidad tenemos:

- Necesidad de contar con ingredientes muy específicos, sólo encontrados a nivel local y temporalmente.

- Técnicas de cocción particulares.

- Uso de determinado tipo de combustibles.

- Utensilios típicos, tradicionales de esa cocina.

- Conocimientos específicos de la "manera de proceder" en la preparación del plato.

Se produce en el tiempo una continua batalla dialéctica entre estas dos cocinas: la cocina popular y la culta.
Se requiere partir en primer lugar de autenticidad en la elaboración de los platos. Las preparaciones de calidad deben estar basadas en recetas, procesos e ingredientes tradicionales. Si intentamos un listado de algunos productos con potencial desarrollo y que conformarían un típico menú peruano, tendriamos por ejemplo:

\section{MENU TRADICIONAL DE EXPORTACION}

- BOCADITOS -

Chifles, cancha

- SALSAS -

Huancaína, ocopa, aji de gallina, ají y huacatay

- ENTRADAS / SEGUNDOS -

Papa a la huancaína

Causa

Arroz con pato

Cau-cau

Cebiche

Aji de gallina

Carapulcra

Humitas

Pepián

Seco de cabrito

Rocoto relleno

Olluco con charqui

- SOPAS -

Puchero

Chupe de camarones

- POSTRES/DULCES -

Mazamorra morada

Arroz con leche

Frejol colado

Picarones

Helados de lúcuma, de chirimoya

Alfajores

Turrón de doña Pepa

Tejas

- BEBIDAS -

Chicha morada

Chicha de jora

Aguas minerales naturales

- COCTELES -

Pisco sour

Algarrobina 


\section{- AGUARDIENTE -}

Pisco

Existen sin duda una serie de otras bebidas, platos y postres muy variados que son aceptados como parte de lo que llamamos cocina peruana, sin embargo hemos realizado una selección entre aquellos que consideramos los más originales, (Zapata, 2001) y al mismo tiempo mayormente preferidos por el público actual. Sobre este punto toda selección inicial no es más que un intento por alcanzar la aceptación de productos en mercados diferentes. Por lo tanto la lista anteriormente presentada no pretende ser ni exhaustiva ni excluyente.

En un contexto más amplio aunque no necesariamente más tradicional, las imágenes de productos comerciales como bebidas gaseosas nacionales, néctares amazónicos, vinos y cervezas nacionales o bizcochos, contribuyen a complementar cualquier comida. La introducción en el mundo internacional de nuestra cocina exigirá de una estrategia concertada, del esfuerzo sostenido y de mucha creatividad, tal como en su momento lo plantearon otras cocinas como las de Tailandia o México por ejemplo.

Algunos puntos que consideramos importantes, aparte de los ya mencionados, dentro del desarrollo, producción y comercialización de comidas, bebidas e insumos con miras a su internacionalización, serían:

1) Las preferencias y gustos de los consumidores, incluyendo los cambios en patrones alimenticios. Comidas variadas étnicamente hablando.

2) Tendencia hacia lo natural, y restricción del uso de aditivos.

3) La diferenciación de productos en función del mercado objetivo (Ej. edades, servicio institucional).

4) La imagen y el diseño del envase final. Se trata de mejorar la presentación de los potajes.

5) En algunos casos deberá contemplarse inclusive el cambio de nombre de los platos.
6) Productos de mayor conveniencia (comodidad) y rapidez en la preparación.

7) Información detallada y veraz sobre los ingredientes (procedencia, recetas, forma de uso) y los platos (origen, historia). Eventualmente se deberá considerar el cambio de nombres en otros idiomas.

8) Signos distintivos como D.O.C. (Denominación de Origen Controlada), sello de garantía (calidad), marcas nacionales.

Tenemos entonces una altemancia histórica de fases, según Revel (1996), entre complejidad y sencillez, pesadez y ligereza, entre reducción de cantidades y presentaciones sobrias. Tendencias entre la internacionalización y la vuelta hacia lo regional, generándose una especie de conflicto permanente entre la valoración de lo tradicional y la invención. La cocina peruana no debe pues rechazar la tradición. Hay una tendencia hacia lo natural y lo fresco, al logro de sabores más refinados con uso de menor cantidad de especias (aji, entre otras), y finalmente un retorno a la naturaleza, aún con el alto costo que esto supone.

\section{VI.- Conclusiones}

La cocina peruana constituye una fuente de inspiración significativa y determinante para la creatividad y capacidad empresarial en el desarrollo de comidas e insumos, que pueden ser tratados como nuevos productos con mayor valor agregado.

Las empresas, según la línea de producción y la actividad productiva generada, principal o complementaria, tienen en este rubro la posibilidad de capitalizar con ventajas la introducción y la expansión comercial en el mercado de una amplísima gama de ingredientes, productos semielaborados y de consumo directo, recetarios, utensilios, etc.

Al mismo tiempo es conveniente señalar la ganancia de la imagen del Perú en el rubro del turismo, pues tanto el sector de Hotelería como el de Restaurantes se verían reforzados notablemente.

Todo lo manifestado anteriormente nos lleva a plantear la necesidad de crear un Pro- 
grama Nacional del Patrimonio Gastronómico Peruano patrocinado por el Estado y ejecutado mayormente por el Empresariado Privado. El reto empresarial planteado supondrá, para el logro de resultados exitosos, integrar eficazmente la experiencia y los conocimientos profesionales en materia de Gastronomía, Tecnologia Alimentaria y Marketing de Nuevos Productos.

Quisiéramos concluir manifestando que de todos los patrimonios culturales, el gastronómico resulta el más agradable, pues no sólo permite calmar necesidades humanas terrenales, sino también y, simultáneamente, conducirnos por los caminos del espíritu, plenos en creatividad, sentimientos y placer.

\section{Sergio Zapata Acha}

Instituto de Investigación

Facultad de Turismo

Universidad de San Martín de Porres, Lima, Perú

szapata21@hotmail.com 


\section{Bibliografía}

\section{ANONIMO}

1895 Nuevo Manual de la Cocina Peruana. Imprenta Librería Francesa Científica y Casa Editorial Galland, Lima.

ANONIMO

1896 La Mesa Peruana o sea el Libro de las Familias.

Imprenta De la Bolsa, Arequipa.

ANONIMO

1918 El Cocinero Peruano. P. Acevedo Editor. Lima.

ANONIMO

2000 "Por Amor a la Cocina"

En: El Comercio, 29 de agosto, Lima.

\section{ANONIMO}

2001a "Tailandia entra por la Cocina"

En: El Comercio, 8 de febrero, Lima.

ANONIMO

2001b "Alimentos Peruanos viajan al Japón"

En: El Comercio, 8 de diciembre, Lima.

ARELLANO, Alexandra

2000 "Echando una Mirada al Tema del

Patrimonio".

En: Turismo y Patrimonio $N^{\circ} 2$. Universidad de San Martín de Porres, Lima.

BERNARD, Alicia \& DOMINGUEZ, Patricia

2002 "Gastronomía. La herencia olvidada". En:

Turismo y Patrimonio en el siglo XXI.

CIET (Centro de Investigaciones y Estudio Turístico), Buenos Aires.

BOIX , Juan

1928 Cocina Práctica, Moderna y Económica con la Criolla del Perú.

Librería e Imprenta Gil, Lima.

CISNEROS, Antonio

1995 "El Mestizaje gastronómico".

En: La Academia en la Olla. Universidad de San Martín de Porres, Lima.

COMBER, Lisa

1992 "Dining Ethnic Style".

En: Dragoco Report 2/92
CROZE, Austin de y CURNONSKY

1933 Trésor Gastronomique de la France. Librarie Delagrave, Paris.

CSERGO, Julia

1997 "La Constitution de la Spécialité Gastronomique Comme Objet Patrimonial en France, fin XVIle - XXe siècle". En: L'esprit des lieuX/Le patrimoine et la Cité. PUG, Grenoble.

GORRITI, Juana María

1890 Cocina Ecléctica.

Editorial Sarmiento (1967), Buenos Aires.

HOLLINSWORTH, Pierce

2000 "Culinary's Expanded Role: Cooking up Product Succes".

En: Food Technology, July, Vol. $54 \mathrm{~N}^{\circ} 7$ : 38-44.

HOCQUENGHEM, Jean Marie y MONZÓN Susana 1995 La Cocina Piurana. CNRS-IFEA-IEP. Lima.

LOPEZ, Gonzalo

2002 "Activación Turística del Patrimonio. Dos ejemplos de Suecia".

En: Turismo y patrimonio en el siglo XXI.

CIET (Centro de Investigaciones y

Estudio Turístico), Buenos Aires.

LOVERA, José

1998 "Raíces de Nuestra Alimentación".

En: Historia de la alimentación en Venezuela. pp. 385-391.

Centro de Estudios Gastronómicos, Venezuela.

PADILLA, Cristina

2002 "Los Sabores del Patrimonio".

En: Turismo y patrimonio en el siglo XXI. CIET (Centro de Investigaciones y Estudio Turístico), Buenos Aires.

PELOSO, Vincent

1988 "La Lucha para Dominar el Modo de Comer en el Perú. Siglo XIX".

En: HISLA. Revista Latinoamericana de Historia Económica y Social. XII, $2^{\circ}$

Semestre, Lima. 
REVEL, Jean-François

1996 Un Festin en Palabras.

Tusquets editores, España.

SCHLÜTER, Regina

2002 "La Gastronomía de la Región Pampeana". En: Turismo y patrimonio en el Siglo XXI. CIET (Centro de Investigaciones y Estudio Turístico), Buenos Aires.

SCHLÜTER, Regina y NORRILD Juana. (Coordinadoras)

2002 "Patrimonio. Características y Usos". En: Turismo y patrimonio en el siglo XXI.

CIET (Centro de Investigaciones y Estudio Turistico), Buenos Aires.

\section{SPAEY, Alain et al.}

1995 La Academia en la Olla. Reflexiones sobre la comida criolla.

Universidad de San Martín de Porres, Lima.

UHL, Susheela

2000 "Spices: Tools for Alternative or Complementary Medicine".

En: Food Technology, May, Vol. 54, No5: 61-66.

\section{URBANO, Henrique}

2000 "Patrimonio y Modernidad".

En: Turismo y patrimonio. 1:13-25. Universidad de San Martín de Porres, Lima.

VALDERRAMA, Mariano

1998 "La Identidad Culinaria del Peruano de Hoy".

En: Ideele, N 105, Lima.
VARGAS, Raúl

1998. "Prólogo".

En: La Academia en la Olla. Universidad de San Martín de Porres, Lima.

\section{VARIOS AUTORES}

2000. Dictionnaire Gastronomique Larousse. 3 Tomos, Paris.

VESA, Marta

1997 "La Cocina Cubana".

En: Conquista y Comida. Consecuencias del encuentro de dos mundos.

Janet Long (Coordinadora). Universidad Nacional Autónoma de México. pp.7187. Segunda edición, México.

YACAR, Susy

2000 "Historias del Buen Gusto. Francia Tierra Predilecta de la Gastronomía".

En: http://www. afuegolento.com

ZAPATA, Sergio

2000 "La Cocina Peruana de Exportación". En: Agroenfoque, Año XV, $N^{\circ} 116: 38$ - 41, Lima.

ZAPATA, Sergio 2001 "Comidas y Bebidas Tradicionales dela Cocina Peruana".

En: Boletín de Lima, Vol. XXIII, N $N^{\circ} 124$ : 37-43, Lima. 